\title{
Risk Assessment of Safety Management Audit Based on Fuzzy TOPSIS Method
}

\author{
Chenning Tian $\mathbb{D}^{1},{ }^{1,2,3}$ Hongxia Li $\mathbb{D}^{1,}{ }^{1,2,3,4}$ Shuicheng Tian $\mathbb{D}^{1,2,3}$ and Fangyuan Tian $\mathbb{D}^{1,2,3}$ \\ ${ }^{1}$ College of Safety Science and Engineering, Xi'an University of Science and Technology, Xi'an 710054, Shaanxi, China \\ ${ }^{2}$ Institute of Safety Management and Risk Control, Xi'an University of Science and Technology, Xi'an 710054, Shaanxi, China \\ ${ }^{3}$ Institute of Safety and Emergency Management, Xi'an University of Science and Technology, Xi'an 710054, Shaanxi, China \\ ${ }^{4}$ College of Management, Xi'an University of Science and Technology, Xi'an 710054, Shaanxi, China
}

Correspondence should be addressed to Hongxia Li; lihx@xust.edu.cn

Received 27 June 2020; Revised 7 November 2020; Accepted 4 December 2020; Published 24 December 2020

Academic Editor: Alessio Ishizaka

Copyright (c) 2020 Chenning Tian et al. This is an open access article distributed under the Creative Commons Attribution License, which permits unrestricted use, distribution, and reproduction in any medium, provided the original work is properly cited.

\begin{abstract}
According to the International Labor Organization (2017), the lack of awareness of safety management leads to 3,000 deaths every day, two every minute, and caused economic losses of 4 percent of global GDP. Also, according to the ILO, 600,000 lives would be saved every year if the available safety management system was used. Therefore, it is necessary to strengthen the audit of safety management and evaluate the risks in the process, which will be conducive to the design of effective safety management methods and reduce the frequency of accidents. Technique for Order Preference by Similarity to an Ideal Solution (TOPSIS) is a common method for audit risk assessment, but in practice, evaluation results obtained using this method are ambiguous as the method relies on individual judgment. Thus, we used the interval-valued intuitionistic fuzzy uncertain language to improve the classical TOPSIS. In this paper, the safety management audit risk evaluation model is structured based on the modern audit risk model from International Auditing and Assurance Standards Board (IAASB). The improved TOPSIS is applied to assess the safety management audit risk from a general perspective. A company is used as the research object to verify safety management audit risk and ranking results of this study. Our empirical results are expected to help companies build future safety management strategies, ensure the safety of the production process, and also realize the sustainable development.
\end{abstract}

\section{Introduction}

Safety accident is an essential public-safety issue facing humanity today. The statistics from the International Labor Organization in 2017 indicate that up to 300 million injuries occur annually with about 2.3 million industrial casualties [1]. This implies that an average of 20 accidents and one death occurs every 15 seconds [2], and economic losses caused by the absence of safety management awareness account for $4 \%$ of the global GDP [1]. Many developed countries began to establish occupational health and safety organizations related in the last century. Britain founded the Health and Safety Executive (HSE) in 1975, and the United States established the Occupational Safety and Health Administration (OSHA) in 1971 [3]. Traffic, construction, mining, agriculture, forestry, fishery, and other basic production industries are associated with high death rates [4]. Currently, death rates in the coal mine industry have declined; however, coal mine accidents frequently threaten the safety of miners [5].China is among the countries with the richest coal reserves and the largest coal producer and consumer globally [6]. Notably, 224 coal mine accidents and 333 deaths in China were reported in 2018. The death rate of millions of tons in coal mines was recorded at 0.093. Investigation reports showed that they are the main causes of the accident including several types of safety management loopholes, lack of safety ideas, backward safety measures, and violation of safety measures [7]. Due to these severe circumstances, several countries have realized the present crisis of coal mine safety management and have taken various countermeasures to improve the current coal mine safety management. Since 2000, China has published many 
coal mine safety management policies including the implementation regulations of the Mine Safety Law, 2004; the Special Provisions of the State Council on the Prevention of Safety Accidents in Coal Mine Production, 2005; the Regulations on the Reporting and Investigation of Safety Accidents in Production, 2007; the Coal Law, 2016; Management Measures for Emergency Plan of Production Safety Accidents, 2016; safety regulations in the coal mine, 2016. However, the current policies mainly prevent the accidents from the macroperspective, enterprise perspective, natural causes, and science and technology and other aspects [8] but do not incorporate safety management controls. Many studies have assessed safety culture, occupational health, and safety management systems [9-11], but no audit assessment of safety management processes has been conducted. Therefore, there is a need to audit safety management in coal enterprises to reduce associated risks. Besides, the risk assessment of safety management can highlight the audit risk and provide effective timely control measures that will reduce the problems in safety management audits.

Many studies on audit risk assessment methods have been applied in government institutions, chemical process industries, and major hazard scenarios, among other areas [12]. However, due to the uncertainty in the process of audit risk assessment, including a lot of fuzzy and uncertain information, it is impossible to accurately evaluate the audit risk. In this study, interval-valued intuitionistic fuzzy uncertain language variables are introduced to reflect the existing uncertainties and improve the decision-making process. On this basis, a new multiattribute decision-making method for security management audit risk assessment is proposed. This method is applied to risk assessment of safety management audit in coal mine enterprises, and its feasibility and effectiveness are demonstrated.

The current safety management audit mainly focuses on the safety management process, while the safety management audit risk assessment can highlight the audit risk in this process, control it in a timely and effective manner, and reduce the problems arising from the safety management audit. To this end, this paper first reviews management audit and safety audit, identifies the similarities and differences between them, and introduces the definition of safety management audit.

\section{Literature Review}

2.1. Safety Management Audit. This study reviews the management audit, safety audit, and safety management.

2.1.1. Management Audit. Different opinions exist on management audit in academic and professional circles since the first report on "management audit" by [13]. However, no consensus has been reached yet. IIA [14] proposed that a management audit is a future-oriented, independent, and systematic evaluation by internal auditors that manage different levels of activities. It purposes to enhance the profitability of an organization by promoting the realization of various management roles, project objectives, social objectives, and staff development. According to Sawyer [15], the management audit examines multiple activities in an organization from a managerial perspective or management consultants. It is different from other audit firms because it focuses on the way of thinking rather than on a technical method. According to Kotler et al. [16], the management audit refers to the management performance evaluation by external personnel. Professor Wang [17], a famous scholar in China, distinguished management audit from internal and external management audit. He highlighted that internal management audit is an independent, objective, comprehensive, constructive, and future-oriented examination and evaluation of management activities in organizations. It helps the management and the fund trustees to improve their decision-making ability and profitability and better perform their fiduciary duties.

As can be seen, management audits are primarily directed at the management of an organization and are audits of management activities. To distinguish it from safety audits, safety audits are reviewed.

2.1.2. Safety Audit. Britain first proposed the concept of road safety audit in the 1970s [18]. Currently, safety audit has been widely applied to electronic information, road traffic, air-traffic control safety, and other fields. However, the definition of a safety audit has not been unified. The safety management audit definition in various fields is summarized in Table 1.

Based on the research reports from various countries, this study defines a safety audit as follows: safety audit is an expert group composed of independent, qualified, and experienced professional audit institutions and their personnel. Safety audit independently, systematically, and formally complies with the performance of the main responsibility of safety production in enterprises. This follows the theory of safety audit and the laws and regulations, national standards, industry standards, enterprise systems, and codes of conduct related to the safety production management of enterprises. It ensures the authority and fairness of the audit results because it is more comprehensive, systematic, and authoritative than safety inspection.

2.1.3. Safety Management. Safety management is regarded as "the management process to achieve freedom from unacceptable risks of harm" [20]. It relates to the actual practices, roles, and functions associated with safety [21]. Safety management has maturely been developed to issue some effective management systems in health and safety implementation and operational guidelines [22]. Safety management can be grouped into macrosafety management and microsafety management following the size of the main body and scope. Microsafety management identifies enterprises as the main body of safety management. It refers to the specific safety management activities carried out by economic and production management departments, enterprises, and institutions. Based on this definition, this study refers to safety as microsafety management [23]. In most industries, safety management relies on coordinated efforts including proper 
TABLE 1: The definition of safety audit in different areas.

Category
$\begin{aligned} & \text { Computer network } \\ & \text { environment safety }\end{aligned}$
$\begin{array}{r}\text { Professional auditors shall, under the provisions of laws and regulations, accept the entrustment of the } \\ \text { owner and the authorization of the management department and systematically and independently } \\ \text { inspect and evaluate the related behaviors in the computer network environment. } \\ \text { According to ICAO standards and recommended measures, national safety production laws and } \\ \text { regulations, civil aviation rules, standards, and normative documents, CAAC conducts safety } \\ \text { compliance inspection on airlines, airports, air-traffic control, and other units. }\end{array}$
A formal study was conducted by a third-party audit team on the current level of safety performance and
practical practices affecting the safety of an organization or enterprise.

planning and control and good HSE management. These collaborative efforts will positively impact on areas such as cost, schedule, safety, and quality [24].

2.1.4. Safety Management Audit. Based on the above literature reports, this paper defines the safety management audit as an independent, systematic, and official regulatory approval for the internal and external environment, rules and regulations, organization structure, employees' qualification, and related behaviors affecting safety management audit related to enterprise safety management. This is based on the theory of safety management and related laws and regulations, national standards, industry standards, enterprise systems, and code of conduct by the independent, qualified, and experienced auditor within the enterprise. By establishing a safety management audit risk evaluation system, the risk existing in enterprise safety management audit can be refined to provide the corresponding evaluation score, intuitively get the risk degree ranking among risk indicators, carry out corresponding rectification, achieve the purpose of prior risk prevention, and improve the enterprise safety management level.

In addition, there are some similarities and differences between safety management audit and financial statement audit. These are shown in Table 2.

2.2. Audit Risk Factors. Safety management audit risk can be assessed by several audit risk indicators. The American Institute of Certified Public Accountants (AICPA) [25] highlighted that the auditor's professional competence, expertise, experience, and the size and organizational structure of the auditee affect the audit risk. Besides, Beaulieu [26] reported that the management quality of the auditee directly affects the audit risk. Elsewhere, Low [27] determined that accounting firms are more inclined to hire auditors with specialized knowledge in a specific industry. Another study by Arens et al. [28] showed that factors affecting audit risk include the operating risk of the auditee, the level of significance, the trust degree of external users of financial reports to financial reports, the moral management level of the auditee, and the possibility of financial difficulties after the auditee issues the audit report. Also, Bédard [29] reported that the internal environmental conditions of the audited units, the safety of the financial accounting system, the attitude of the management in preventing and correcting misstatement risk occurrence, the organizational structure of the audited units, the participation of all personnel, and other factors all have impacts on the audit control risk. Yang and Chang [30] conducted a questionnaire survey on the causes of audit risk of listed companies. They reported that there were five main causes of audit risk including the listed company itself, the rules and regulations, environmental factors, the accounting firm itself, and the audit system of the listed company. Conclusively, the audit risk factors are in five categories including the economic environment, legal environment, political environment, industry environment, and human environment. Of note, based on the content of the audit risk factors, safety management audit definition, the safety management audit risk factors, and factors influencing audit risk are similar and they include the political, legal, industrial, human, and economic environments. However, the effects of the economic environment on safety management audit risk are smaller compared with the general audit risk degree.

Moreover, the factors influencing audit risk, safety management audit definition, and safety management audit risk are similar and include political, legal, industrial, human, and economic environments. However, the impact of the economic environment on safety management audit risk is less than that on ordinary audit risk.

\subsection{Fuzzy Multiple Attribute Decision-Making Method.} Multiattribute decision-making is an important part of decision theory [31]. The MADM mainly solves the problem of sorting and selecting the best alternatives. Fuzzy set theory has widely been used to study fuzzy multiattribute decisionmaking problems since its first proposal by Zadeh [32]. Also, Baas and Kwakernaak [33] highlighted the classical fuzzy multiattribute decision-making method which transforms the fuzzy set theory into a methodology. It is used to solve multiattribute decision-making problems effectively. Additionally, Chen and Hwang [34] systematically introduced 14 fuzzy multiattribute decision-making methods including maximization-minimum method, maximization-maximum method, the linear distribution method, Elimination Et Choice Translating Reality (ELECTRE), and TOPSIS. The development of the fuzzy set theory and method has gradually enriched the multiattribute decision-making method with the fuzzy set. However, the traditional fuzzy set cannot accurately and comprehensively express the information [35]. Later, Atanassov [36, 37] expounded the fuzzy set and proposed the concept of the intuitionistic fuzzy set which used a membership function $\left[\mu_{A}(X)\right]$ and a nonmembership function $\left[v_{A}(X)\right]$ to describe the intuitionistic 
TABLE 2: Similarities and differences between safety management audits and financial statement audits.

\begin{tabular}{lll}
\hline & Differences & Similarities \\
\hline $\begin{array}{l}\text { Safety } \\
\text { management } \\
\text { audit }\end{array}$ & $\begin{array}{l}\text { (1) The object of the audit was safety management } \\
\text { performance and safety management activities. }\end{array}$ & $\begin{array}{l}\text { (1) Both audits involve a reassessment of the performance of } \\
\text { fiduciary responsibilities and the issuance of a critical audit } \\
\text { opinion. }\end{array}$ \\
& $\begin{array}{l}\text { (2) The safety management audit issued an audit } \\
\text { opinion based on "reasonable management } \\
\text { standards." }\end{array}$ & $\begin{array}{l}\text { (2) Both audits are in a system of dual accountability, where } \\
\text { the auditor is responsible for the audit opinion and the } \\
\text { fiduciary (manager) is responsible for the business. }\end{array}$ \\
\hline $\begin{array}{l}\text { Financial } \\
\text { statement audit The object of the audit was the financial statements }\end{array}$ & $\begin{array}{l}\text { (3) Both audits share a common form of role; firstly, they both } \\
\text { and the internal control structure used in their } \\
\text { preparation. }\end{array}$ & $\begin{array}{l}\text { inform the science of decision-making for the principal; } \\
\text { secondly, through the assurance function, both can provide } \\
\text { information about the business, and finally, through } \\
\text { constructive intelligence, both can advise the trustees on how } \\
\text { to improve management. }\end{array}$ \\
\hline
\end{tabular}

fuzzy set. However, in the actual decision-making environment, membership and nonmembership degrees are often problematic in giving accurate values. Therefore, in 1989, Atanassov and Gargov [38] proposed the intuitionistic fuzzy set of interval values and developed the two scales in IFSs into membership and nonmembership zones in IVIFSs. Later, in 1999, Atanassov [39] enhanced the expression ability of uncertain information making it more flexible and suitable in dealing with realistic uncertainty and ambiguity. Fuzziness and uncertainty generally exist in actual decisionmaking. In the evaluation process, decision-makers tend to use uncertain language to describe uncertainty because it effectively reflects the ambiguity of human thinking. For example, when evaluating risks, people are more likely to use uncertain languages such as "low," "medium," and "high." If the intuitionistic linguistic set is used to describe this hesitation, the uncertain information can model more accurately. Besides, Wang and $\mathrm{Li}$ [40] introduced language evaluation information into the intuitive fuzzy set (IFS). They showed the related concepts and properties of the intuitive linguistic set (ILS) and studied the multiattribute decision-making method based on ILs. Another report by Wang et al. [41] indicated the weighted geometric average operator, ordered weighted geometric operator, and mixed geometric operator based on ILs. They were applied in multiple attribute decision-making with the attribute value as intuitionistic language information. Ju and Yang [42] introduced trapezoidal fuzzy numbers into ILs and identified the related concepts and properties of intuitionistic trapezoidal fuzzy language information. Based on the binary fuzzy linguistic representation model and preference relation, Zhang et al. [43] provided the definition and properties of binary intuitionistic fuzzy semantic preference relation. They highlighted the group decision-making method based on binary intuitionistic fuzzy semantic preference relation. Also, Liu [44] extended the intuitionistic fuzzy language variable and proposed interval-valued intuitionistic fuzzy uncertain language variable. A multicriteria group decisionmaking (MCGDM) approach based on Pythagorean fuzzy uncertain linguistic variables (PFULVs) was proposed by Liu et al. [45]. Zeng et al. [46] extended the fuzzy TOPSIS method and applied it to enterprise resource planning systems. In this review, the interval-valued intuitionistic fuzzy uncertain language decision-making method and
TOPSIS method of partial weight information were selected to evaluate the audit risk of safety management in mining companies. This method eliminates the possibility of inaccuracy and nonpersonalization caused by excess subjective weight in the TOPSIS method. It thereby improves the objectivity and scientific standard of the evaluation results.

\section{Data}

3.1. Identifying the Safety Management Audit Indicators. The selection of safety management audit risk assessment indicators should conform to the definition of the four elements of safety management (people, machine, environment, and management) and have certain characteristics of the selected indicators.

3.2. Characteristics of Safety Management Audit Indicators. Safety management audit risk indicators exhibit the following characteristics in the evaluation process:

(1) Universality: safety management audit risk is universal and exists in every link of the safety management audit process. An audit error in any link will increase the risk of final audit failure. Therefore, it is important to evaluate the universality of the audit risk index of safety management to correct the final audit result.

(2) Controllability: safety management audit risk indicators should be accurately identified in the audit process and the possibility of audit risk is controlled by identifying risks and taking corresponding measures.

(3) Relevancy: the evaluation of safety management risk indicators by experts is closely related to the final audit results. Changes in the evaluation results will change the audit results.

By evaluating and analyzing the risk indicators that conform to the selection principle for risk indicators of safety management audit from the three aspects of universality, controllability, and relevance, risks in the safety management audit process can be accurately identified and controlled. 
3.3. Selection of Safety Management Audit Indicators. According to the definition of the safety management audit, the relevant literature data are reviewed and the relevant experts are interviewed. This is based on the investigation of the current situation of the enterprise safety management audit. In this paper, 27 indicators were preliminarily selected as alternative indicators. The specific indicators are shown in Figure 1.

In the (no. 47) audit standard statement issued by the American Institute of Certified Public Accountants, a calculation model of audit risk is proposed as audit risk $=$ risk of material misstatement (RMM) * detection risk (DR) (Auditing Standards Board, AICPA, New York, 1983).

Following the literature content summary, expert research, and other methods, the 27 alternative indicators were grouped into material misstatement risk and inspection risk. The corresponding details were reviewed to obtain the final 21 safety management audit risk evaluation indicators. The specific content is shown in Figure 2.

3.4. Data Collection. A scoring table showing safety management audit risk evaluation indexes was generated after clarifying the evaluation indexes and characteristics of safety management audit risks (Table 3 ).

Two scoring methods were adopted in the scoring process, namely, the five-level evaluation method and interval-valued intuitionistic fuzzy language evaluation method. In the two scoring methods, 1-5 corresponds to very low, low, medium, high, and very high, respectively. However, with the interval-valued intuitionistic fuzzy language, the specific definition of the degree of representation for each rank is not given. The judgment should be based on the understanding of experts themselves. For example, if experts believe that in the auditing safety management process, the political and legal environment has a high degree of influence on the auditing phenomenon and can, therefore, choose 4-5 or 3-4. Similarly, the degree of inclination should be filled in a specific interval. For example, if experts believe that the higher degree of universality lies in the interval 4-5 and the definition of "higher" is more likely to be 4 and not 5 , then, $0.8-0.9$ (or $0.6-0.7$ or $0.7-0.8$ ) should be filled in the 4 th interval and $0.1-0.2$ (or $0.3-0.4$ or $0.2-0.3$ ) should be filled in the 5 th interval.

This study selected the HLL mining company as an example whereby the management personnel, safety managers, and internal auditors were selected to evaluate the risk indicators of the company's safety management audit.

\section{Methodology}

4.1. Interval-Valued Intuitionistic Fuzzy Uncertain Language (IVIFUL). Let $S=\left\{s_{1}, s_{2}, s_{3}, \ldots, s_{l}\right\}$ be a finite, completely ordered, discrete set of words. For example, a language set with five language variables can be expressed as $S=$ $\left\{s_{1}=\right.$ extremely poor, $s_{2}=$ poor, $s_{3}=$ fair, $s_{4}=$ good, $s_{5}=$ extremely good $\}$. In order to preserve all the information in the decision-making process, the discrete set $S$ of linguistic variables is extended to the continuous set of linguistic variables $\bar{S}=\left\{s_{\alpha} \mid \alpha t \in n R\right\}$.
Definition 1. Let $\widetilde{A}=\left\{\left\langle x_{i}, \tilde{h}_{\tilde{A}}\left(x_{i}\right)\right\rangle \mid x_{i} \in X, i=1,2, \ldots, n\right\}$ be the set of hesitating fuzzy linguistic variables, where $\widetilde{h}_{\tilde{A}}\left(x_{i}\right)=\left\{\left(\widetilde{s}_{\theta_{i}}, \operatorname{lh}\left(s_{\theta_{i}}\right)\right) \mid \widetilde{s}_{\theta_{i}} t \in n \bar{S}\right\} \quad$ represents all possible hesitant fuzzy language information of $x_{i} \in X, \operatorname{LH}\left(\bar{S}_{\theta_{i}}\right)=$ $\left\{r_{1}, r_{2}, \ldots, r_{m i}\right\}$ is all the membership, and $\left(\widetilde{s}_{\theta_{i}}, \operatorname{lh}\left(\widetilde{s}_{\theta_{i}}\right)\right)$ is the fuzzy linguistic variable. Let $\widetilde{h} \sim\left(x_{i}\right)$ represent hesitating fuzzy linguistic element (HFLE) [44].

Definition 2. Let $\widetilde{a}_{i}=\left(\widetilde{s}_{\theta_{i}}, \operatorname{lh}\left(\widetilde{s}_{\theta_{i}}\right)\right)$ be the fuzzy linguistic variable, then the expectation function can be defined as

$$
E\left(\left(\widetilde{s}_{\theta_{i}}, \operatorname{lh}\left(\widetilde{s}_{\theta_{i}}\right)\right)\right)=\frac{\theta_{i}}{\left|\ln \left(\widetilde{s}_{\theta_{i}}\right)\right|} \sum_{r_{i} \in \operatorname{lh}\left(\widetilde{s}_{\theta_{i}}\right)} r_{i}
$$

where $\left|\operatorname{lh}\left(\widetilde{s}_{\theta_{i}}\right)\right|$ represents the number of membership degrees in $\operatorname{lh}\left(\tilde{s}_{\theta_{i}}\right)$.

Let $\tilde{a}_{i}=\left(\widetilde{s}_{\theta_{i}}, \operatorname{lh}\left(\widetilde{s}_{\theta_{i}}\right)\right)$ and $\widetilde{a}_{j}=\left(\widetilde{s}_{\theta_{j}}, \operatorname{lh}\left(\widetilde{s}_{\theta_{j}}\right)\right)$ be two fuzzy linguistic variables, if $E\left(\widetilde{a}_{i}\right)<E\left(\tilde{a}_{j}\right)$, then $\widetilde{a}_{i}<\widetilde{a}_{j}$ [44].

Definition 3. If $\widetilde{h}_{i}=\left\{\left(\widetilde{s}_{\theta_{i}^{2}}, \operatorname{lh}\left(\widetilde{s}_{\theta_{i}^{2}}\right)\right)\right\}$ and $\widetilde{h}_{i}=\left\{\left(\widetilde{s}_{\theta_{j}^{2}}, \operatorname{lh}\left(\widetilde{s}_{\theta_{j}^{2}}\right)\right)\right\}$ are two hesitant fuzzy linguistic elements, then the distance between $a$ and $B$ is defined as

$$
\begin{aligned}
& d\left(\widetilde{h}_{1}, \widetilde{h}_{2}\right)=\frac{1}{2 m\left(\widetilde{s}_{\theta_{i}^{1}}\right)} \sum\left(\left(\frac{\left|\theta_{\sigma(i)}^{1}-\theta_{\sigma(j)}^{2}\right|}{9}+\frac{1}{\left|\operatorname{lh}\left(\widetilde{s}_{\theta_{j}^{2}}\right)\right|}\right)\right. \\
& \left.\times\left(\sum_{r_{\sigma(i)}^{1} \in \ln \left(\tilde{s}_{\theta_{j}^{1}}\right), r_{\sigma(i)}^{2} \in \ln \left(\tilde{s}_{\theta_{j}^{2}}\right)}^{\left|r_{\sigma(i)}^{1}-r_{\sigma(i)}^{2}\right|}\right)\right),
\end{aligned}
$$

where $m\left(\widetilde{s}_{\theta^{1}}\right)$ represents the number of language variables contained in $\widetilde{h}_{1}$ and $\left|\operatorname{lh}\left(\widetilde{s}_{\theta^{2}}\right)\right|$ represents the number of membership degrees contained in $\operatorname{lh}\left(\widetilde{s}_{\theta_{i}^{2}}\right)$.

Easy to verify, the above definition meets the following:

(1) $0 \leq d\left(\tilde{h}_{1}, \tilde{h}_{2}\right) \leq 1$

(2) $d\left(\widetilde{h}_{1}, \widetilde{h}_{2}\right)=0$ if and only if $\widetilde{h}_{1}=\widetilde{h}_{2}$

(3) $d\left(\tilde{h}_{1}, \tilde{h}_{2}\right)=d\left(\tilde{h}_{2}, \tilde{h}_{1}\right)[44]$

4.2. Classical TOPSIS. As one of the classic multiattribute decision-making methods, the TOPSIS method was first put forward by Hwang and Yoon [47]. It is mainly through building the decision-making problem of positive and negative ideal solution, using the two benchmark methods of approaching positive ideal solution and deviating from negative ideal solution as the judgment conditions of evaluating each decision-making scheme, and getting the ranking results of decision-making problems, so as to make decisions [48, 49].

Recently, a lot of research papers about safety management were published on TOPSIS theories and applications [50-54]. In this paper, the TOPSIS method is improved with IVIFUL.

4.3. Improved IVIFUL TOPSIS. There is a multiattribute decision problem. $A=\left\{A_{1}, A_{2}, \ldots, A_{m}\right\}$ is the scheme set, 


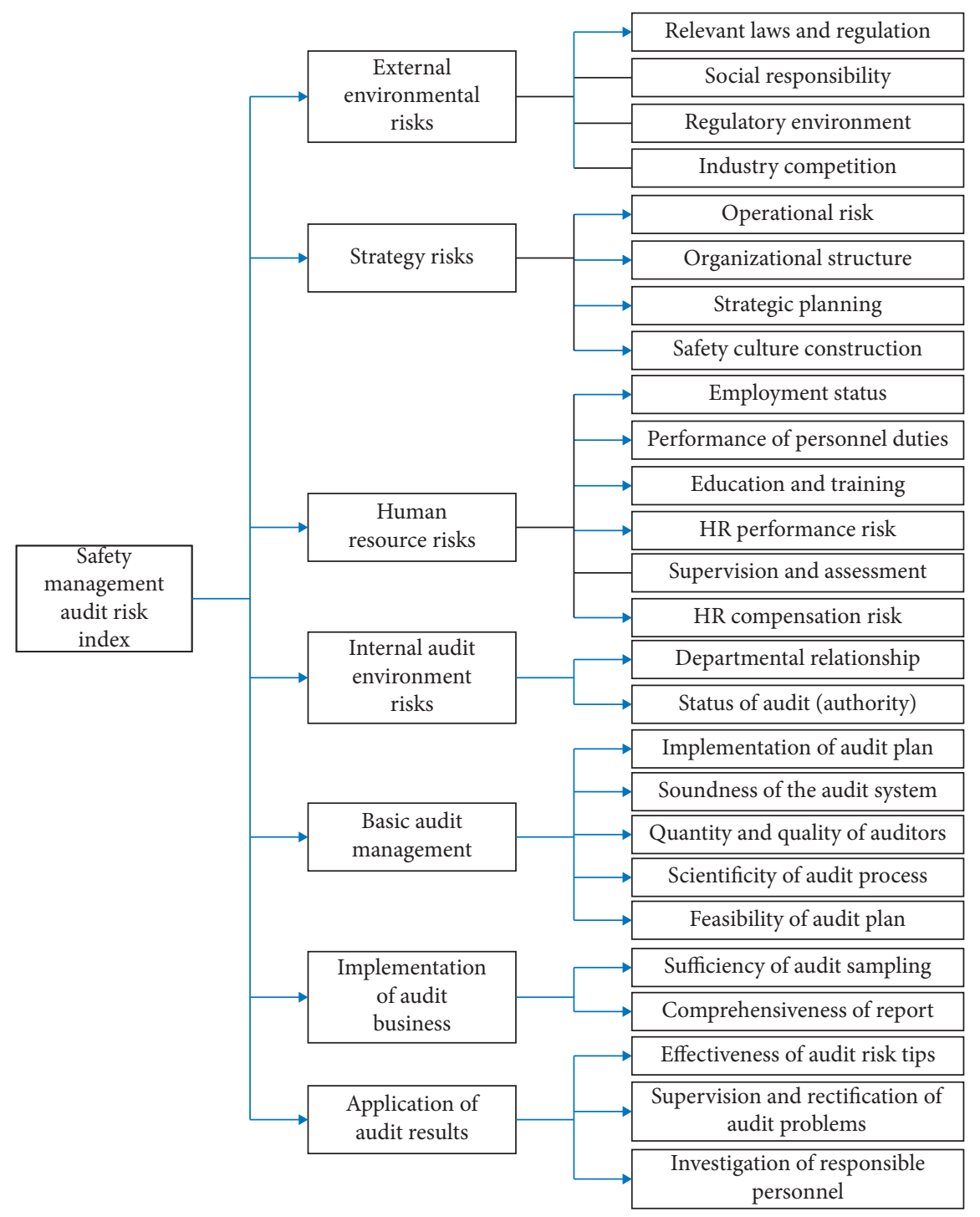

FIGURE 1: Safety management audit risk alternative index.

and $C=\left\{C_{1}, C_{2}, \ldots, C_{n}\right\}$ is the attribute set. Because of the complexity of decision-making problem and fuzzy uncertainty of human thinking, decision-makers will show hesitation in evaluation. They use language variables to evaluate the scheme and give the membership degree of the scheme. If the decision-maker is familiar with the attribute, the evaluation value of the scheme can be given, if the decision-maker is not familiar with the attribute, the decision-maker can use the appropriate number of language variables to evaluate according to his own situation. Then, the information obtained is hesitation fuzzy language information. The decision-maker gives the evaluation value of the scheme's attributes to constitute the decision matrix $\widetilde{D}=\left(\widetilde{h}_{i j}\right)_{m \times n}$, where $\widetilde{h}_{i j}$ is the hesitant fuzzy language information.

In some decisions, the weight information of attributes is partially known. Generally, the weight information of partially known attributes can be expressed as a subset of the following sets:

$$
\begin{aligned}
H= & \left\{\omega_{i} \geq \omega_{j} ; \omega_{i}-\omega_{j} \geq \varepsilon_{i}(\geq 0) ; \omega_{i} \geq \alpha_{i} \omega_{j}, 0 \leq \alpha_{i} \leq 1 ; \beta_{j}\right. \\
& \leq \omega_{j} \leq \beta_{j}+\varepsilon_{i}, 0 \leq \beta_{j}<\beta_{j}+\varepsilon_{j} \leq 1 ; \omega_{i}-\omega_{j} \\
& \left.\geq \omega_{k}-\omega_{l}, \quad \text { for } i \neq j \neq k \neq l\right\} .
\end{aligned}
$$

Based on the information theory, we give the maximum deviation method. According to information theory, if the deviation between the evaluation value of an attribute and the evaluation value of the same attribute of all schemes is small, the contribution of the attribute is relatively small, so it should be assigned a smaller weight; otherwise, it should be assigned a larger weight. We use the maximum deviation method to calculate the weight vector of the attribute.

Let $\widetilde{h}_{i j}=\left\{\left(\widetilde{s}_{\theta_{i j}}, \operatorname{lh}\left(\widetilde{s}_{\theta_{i j}}\right)\right)\right\}, \widetilde{h}_{k j}=\left\{\left(\widetilde{s}_{\theta_{k j}}, \operatorname{lh}\left(\widetilde{s}_{\theta_{k j}}\right)\right)\right\}$ be two hesitant fuzzy language elements, the distance between $\tilde{h}_{i j}$ and $\widetilde{h}_{k j}$ is defined as 


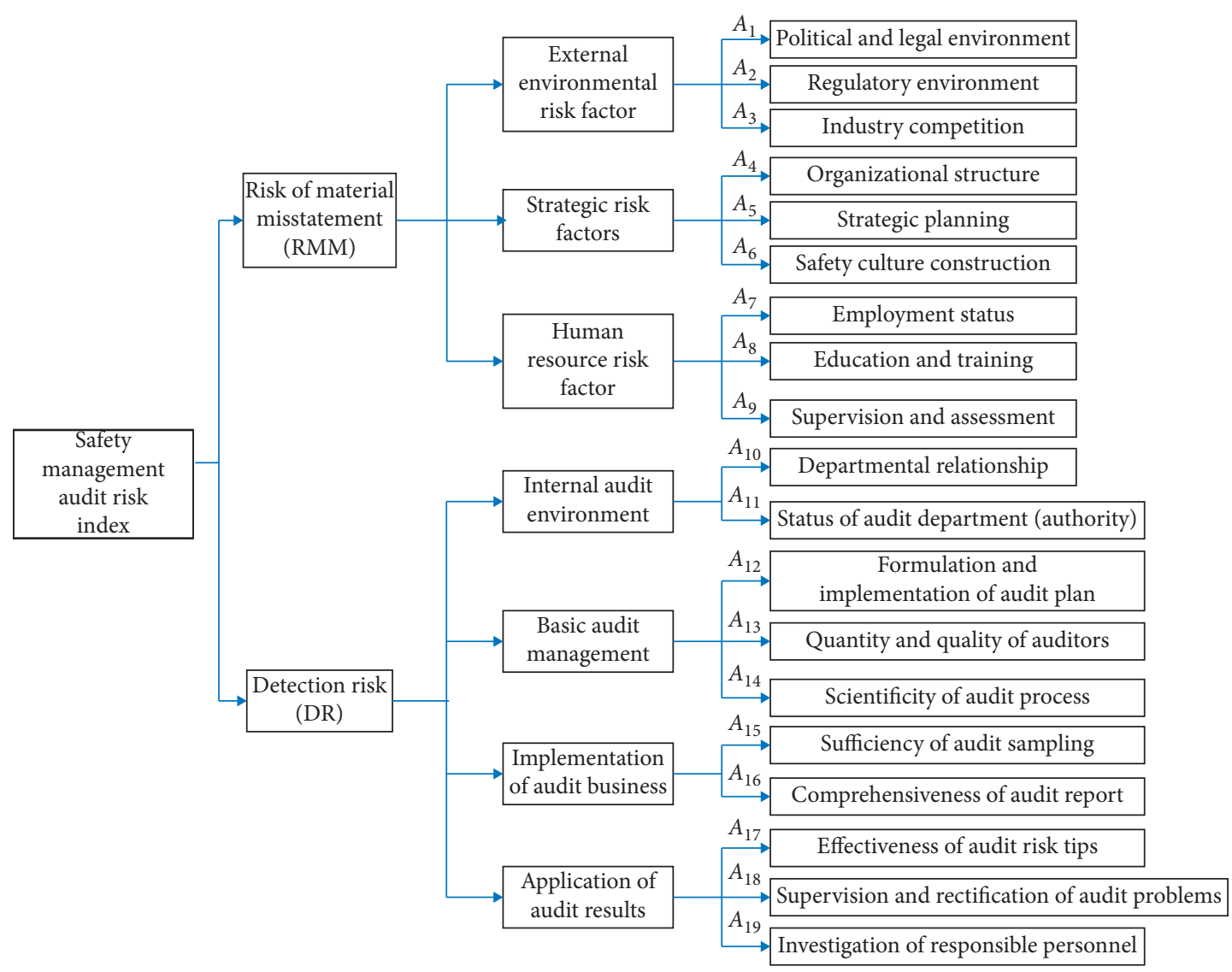

FIGURE 2: Safety management audit risk index.

TABLE 3: Safety management audit risk index scoring table.

\begin{tabular}{|c|c|c|c|c|c|}
\hline Goal & Subsystem level & Index & Universality & Controllability & Relevant \\
\hline RMM & $\begin{array}{l}\text { External environmental risk factors } \\
\text { Strategic risk factors } \\
\text { Human resource risk factors }\end{array}$ & $\begin{array}{c}A_{1} \\
A_{2} \\
A_{3} \\
A_{4} \\
A_{5} \\
A_{6} \\
A_{7} \\
A_{8} \\
A_{9}\end{array}$ & & & \\
\hline DR & $\begin{array}{c}\text { Internal audit environment } \\
\text { Basic audit management } \\
\text { Implementation of audit business } \\
\text { Application of audit results }\end{array}$ & $\begin{array}{l}A_{10} \\
A_{11} \\
A_{12} \\
A_{13} \\
A_{14} \\
A_{15} \\
A_{16} \\
A_{17} \\
A_{18} \\
A_{19}\end{array}$ & & & \\
\hline
\end{tabular}




$$
\begin{aligned}
d\left(\widetilde{h}_{i j}, \tilde{h}_{k j}\right)= & \frac{1}{2 m\left(\tilde{s}_{\theta_{i j}}\right)} \sum\left(\frac{\left(\left|\theta_{i \sigma(j)}-\theta_{k \sigma(j)}\right|\right)}{9}+\frac{1}{\left|\ln \left(\tilde{s}_{\theta_{i j}}\right)\right|}\right. \\
& \times\left(\sum_{r_{i \sigma(j)}^{1} \in \ln \left(\left(\tilde{s}_{\theta_{i j}}\right)\right), r_{k \sigma(j)}^{2} \in \ln \left(\left(\tilde{s}_{\theta_{k j}}\right)\right)}^{\left.\left|r_{i \sigma(j)}^{1}-r_{k \sigma(j)}^{2}\right|\right)}\right),
\end{aligned}
$$

and the deviation of the scheme with respect to all evaluation values of attribute $C$ can be expressed as $\sum_{k=1}^{m} \sum_{i=1}^{m} d\left(\widetilde{h}_{i j}, \widetilde{h}_{k j}\right)$

A reasonable weight should maximize the deviation, so we establish the following model:

$$
\begin{aligned}
& (M-1) \max D(W)=\sum_{j=1}^{n} \omega_{j}\left(\sum_{k=1}^{m} \sum_{i=1}^{m} d\left(\tilde{h}_{i j}, \widetilde{h}_{k j}\right)\right), \\
& \text { s.t. } \omega \in H, \omega_{j} \geq o, j=1,2, \ldots, n, \omega_{1}+\omega_{2}+\cdots+\omega_{n}=1 .
\end{aligned}
$$

The model $(M-1)$ is a linear programming model, which can be solved by the method of interior point.

Next, a multiattribute decision-making method based on maximum deviation and TOPSIS is proposed.

Step 1 . The decision matrix $\widetilde{D}=\left(\widetilde{h}_{i j}\right)_{m \times n}$ is obtained by adding the smallest fuzzy language elements to make each hesitant fuzzy language element contain the same number of fuzzy language elements.

Step 2. Solving the model $(M-1)$ to get the weight vector $W=\left(\omega_{1}+\omega_{2}+\cdots+\omega_{n}\right)$ of the attribute.

Step 3. Calculation of weighted hesitant fuzzy linguistic decision matrix, $\widetilde{D}^{\prime}=\left(\widetilde{h}_{i j}^{\prime}\right)_{m \times n}$ where $\widetilde{h}_{i j}^{\prime}=\omega_{j} \widetilde{h}_{i j}$.

Step 4. Determining a positive ideal solution

$$
\begin{aligned}
H^{+} & =\left\{h_{1}^{+}, h_{2}^{+}, \ldots, h_{n}^{+}\right\} \\
& =\left\{\max \widetilde{h}_{i 1}^{\prime}, \max \widetilde{h}_{i 2}^{\prime}, \ldots, \max \widetilde{h}_{i n}^{\prime}\right\},
\end{aligned}
$$

and a negative ideal solution

$$
\begin{aligned}
H^{+} & =\left\{h_{1}^{-}, h_{2}^{-}, \ldots, h_{n}^{-}\right\} \\
& =\left\{\min \widetilde{h}_{i 1}^{\prime}, \min \widetilde{h}_{i 2}^{\prime}, \ldots, \min \tilde{h}_{i n}^{\prime}\right\},
\end{aligned}
$$

of hesitant fuzzy language.

Step 5. Calculating the distance between the weighted evaluation value of each scheme and the positive and negative ideal solution of hesitant fuzzy language:

$$
\begin{aligned}
d_{i}^{+} & =\sum_{j=1}^{n} d\left(\widetilde{h}_{i j}^{\prime}, \widetilde{h}_{j}^{+}\right), d_{i}^{-} \\
& =\sum_{j=1}^{n} d\left(\widetilde{h}_{i j}^{\prime}, \widetilde{h}_{j}^{-}\right), \quad i=1,2, \ldots, m .
\end{aligned}
$$

Step 6. Calculate the relative closeness of the scheme $C_{i}=d_{i}^{-} /\left(d_{i}^{+}+d_{i}^{-}\right), i=1,2, \ldots, m$.
According to the relative closeness of the scheme, the scheme is sorted and the optimal scheme is selected.

Compared with the classical TPSIS method, the improved IVIFUL TOPSIS method can better avoid the possibility of inaccuracy and unindividuation caused by excessive subjective weight.

\section{Results}

The case company is one of the large-scale mines planned by the National Development and Reform Commission in Shenfu South District. It has won many honorary titles such as national safety and quality standardization coal mine, national safety culture construction demonstration enterprise, and national enterprise culture excellent case, among others. This study purposed to help the company perform a risk assessment on potential risk factors of safety management audit and determine the possibility of audit risk.

5.1. Classical TOPSIS Results. The overall risk index score of the safety management audit is obtained using the classical TOPSIS method. Each index was ranked by the weight vector of the three decision-makers. Changes in the index ranking are shown in Figure 3.

The experts gave the same score and calculated the results which yielded similar ranking and risk degree of the risk indicators (Figure 3). This scenario is almost impossible in the daily safety production management process because it ignores the preference and fuzziness of experts in evaluating risk indicators. Moreover, its internal evaluation criteria make it difficult to make a more detailed analysis of risk indicators by using the classical TOPSIS method which is not conducive to further decision-making. Therefore, the improved TOPSIS method is used to re-evaluate the above risk indicators to perform comparative analysis and obtain more objective evaluation results.

5.2. Improved TOPSIS Results. A committee composed of the company manager, safety manager, and internal auditor was established to assess the risk of each characteristic of each safety management audit risk index. Their different experience and knowledge were considered, and the weight vector of the three decision-makers was determined as $l=(0.45,0.3,0.25)$.

Using the improved TOPSIS method, the overall risk index score for the safety management audit was obtained. Each index was ranked by the weight vector of the three decision-makers. The index ranking is shown in Figure 4.

After assessing the risk indicators by the company managers, safety managers, and internal auditors, it was reported that $A_{18}, A_{19}$, and $A_{13}$ were among the top ten indicators with the highest risk according to the three groups of experts. Besides, $A_{18}$ and $A_{19}$ were the two leading factors in evaluating of three groups of experts. This showed that the accountability for negligence and the rectification of hidden dangers will have an impact on the safety management audit regardless of the management level or the staff level. Also, the other top-five risk indicators included $A_{13}, A_{16}$, and $A_{8}$. 


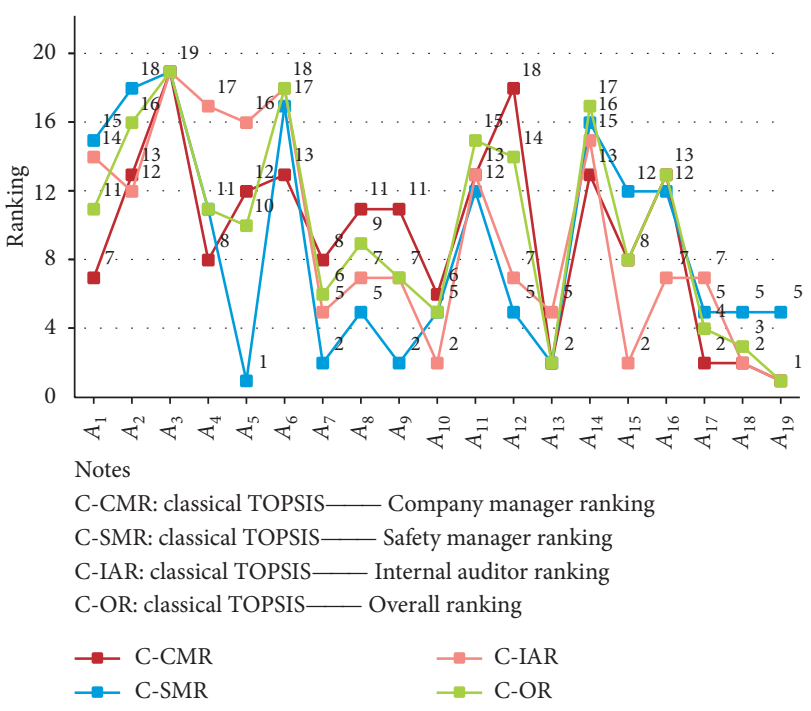

FIGURE 3: Index ranking of safety management audit by classical TOPSIS.

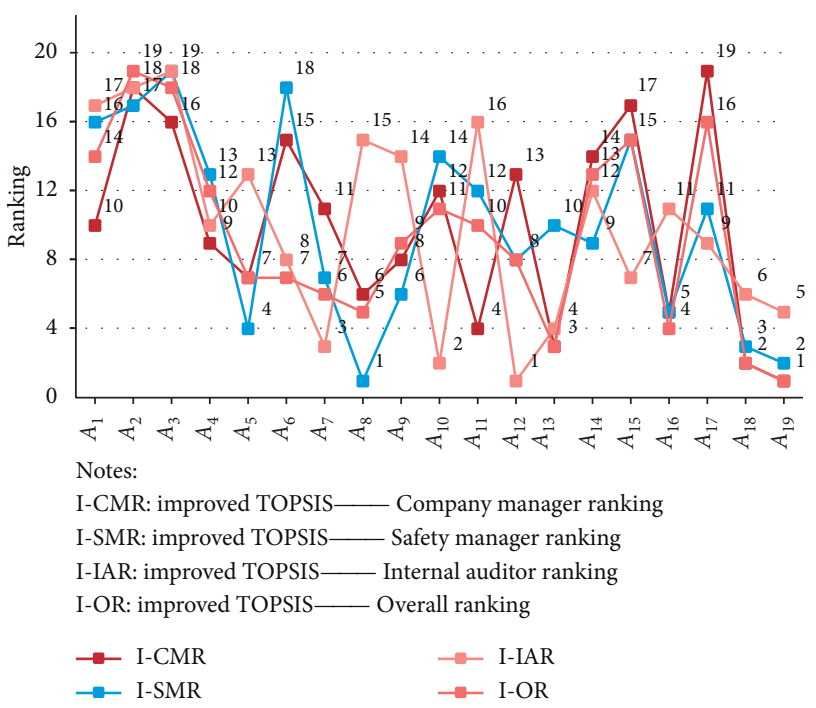

FIGURE 4: Index ranking of safety management audit by improved TOPSIS.

From the above results, it can be concluded that the safety management audit can indirectly improve the vigilance of other employees to safety management risks. This is by supervising and rectifying the relevant risks and investigating the relevant responsibilities of the negligent individuals. Second, listening to the safety management training personnel can strengthen the safety awareness of employees. Through various forms of training, the awareness of safety production is availed into the daily life of employees thereby can effectively reduce risk. Third, the comprehensiveness of the audit reports influences safety management audit. A comprehensive safety management audit can maximize the value of the enterprise safety management audit and effectively enhance the effect of the audit work.

The improved TOPSIS was used to analyze the evaluation of three groups of experts and the comprehensive ranking of 19 risk factors showed as the highest-ranking risk factor. In ranking the safety managers and internal auditors, $A_{19}$ ranked second and fifth places, respectively. However, $A_{5}$ 's final ranking varies, and $A_{5}$ ranks $7^{\text {th }}$ and $13^{\text {th }}$ in ranking the safety managers and internal auditors, respectively (Figure 4). Therefore, it is important to compare the results from separate analyses.

$A_{17}$ effectiveness of audit risk tips is ranked $19^{\text {th }}$ in the evaluation results of the management, and it is the last one among the risk indicators (Figure 4). However, it ranks at $11^{\text {th }}$ and $10^{\text {th }}$ place in the evaluation results for safety managers and internal auditors, respectively, which is significantly higher than the ranking position in the management. Notably, it has a high positive impact on the daily safety production of employees to prompt the known risks, highlights the basic risk prompt of production and operation, and sounds a warning to the employees and relevant safety manager thereby reducing the possibility of various accidents in daily safety production. Other indicators with wide deviations in rankings are $A_{5}, A_{9}, A_{10}$, and $A_{15}$. They were considered unstable for this level of safety management audit. In addition, for some risk indicators, the ranking was relatively consistent in different analysis methods (Figure 4). These indicators are $A_{3}, A_{6}, A_{13}, A_{14}, A_{18}$, and $A_{19}$.

\section{Discussion}

By summarizing the definitions and characteristics of management audit, safety audit, and safety management, we have revealed the specific risk indicators of safety management audit which can be applied during safety management audit. The risk index proposed here can accurately and reasonably reflect the risks and hidden dangers in the safety management audit of audited enterprise.

The classical TOPSIS method is improved by using the attribute weight calculation method of interval intuitionistic fuzzy uncertain linguistic information. Taking coal enterprise as the object, a safety management audit risk evaluation model is constructed based on the improved TOPSIS method. Compared with the classical TOPSIS method, the improved TOPSIS method is less likely to obtain the same evaluation between different indicators, more in line with the current situation, and more scientific, reasonable, and applicable in practice.

The classical TOPSIS method and the improved TOPSIS method are used to conduct risk assessment of the safety management audit of the company from three perspectives: company manager, safety manager, and internal auditor. Our results show that identification of risks improves the company's safety management. In addition, the professionalism of auditors and the comprehensiveness of audit reports play an important role in safety management audit. On this basis, according to the level of importance of the risk, we suggest rectification approaches for improving safety management level in enterprises.

First, considering the impact of risk indicator $A_{18}$ supervision and rectification of audit problems and $A_{19}$ investigation of responsible personnel, it is suggested that relevant responsible persons should be accountable for the audit results after the auditing process. Similarly, special 
personnel should be assigned to supervise and urge the rectification of the existing risk factors presented in the audit results. Of note, each item should be adopted separately by taking the practical rectification measures and completing rectification of the potential risks comprehensively, thoroughly, and rapidly. Also, the potential risks must be eliminated early to resolutely prevent them from evolving into major safety production accidents and major environmental pollution events. This will ensure environmental safety and production safety.

Second, considering the impact of risk indicator $A_{13}$ quantity and quality of auditors, it is suggested that the company needs to establish a special internal audit department to audit its safety management or simplify the existing safety management auditors. However, this should be done adequately to improve the professional quality and structure of auditors. Notably, a safety management audit is part of the internal audit. Enterprises should constantly improve the organizational safety management audit work system. Strengthening the audit system in an organization and improve the independence and objectivity of safety management audit.

Third, considering the impact of the risk indicator comprehensiveness of the audit report, it is suggested that the company should improve the final audit report, notification, and prompt. A complete audit report can comprehensively summarize the purpose, scope, and results of an audit. Through the safety management audit report, managers effectively identify the current situation and hidden dangers and develop a quick and effective safety management plan for the enterprise. Similarly, the safety management audit report provides relevant and detailed information on safety management that other reports cannot provide. The management and safety production details provide objective information useful for safety managers in promoting safety management standardization. Therefore, the enterprise safety management audit department should provide timely reports or feedback, report problems, and prompt risks during and after the audit.

\section{Data Availability}

The data used to support the findings of this study are available from the first author upon request (Chenning Tian 19120089021@stu.xust.edu.cn).

\section{Conflicts of Interest}

The authors declare that they have no conflicts of interest.

\section{Acknowledgments}

This work was supported by the National Natural Science Foundation of China (grant nos. 51874237 and U1904210).

\section{References}

[1] ILO, "International labour standards on occupational safety and health," 2017, https://www.ilo.org/global/standards/subjectscovered-by-international-labour-standards/occupational-safetyand-health/lang--en/index.htm.
[2] H. Y. Chen, Construction of Database Model for Security Management System of Emerging Industries, University Of International Business And Economics, Beijing, China, 2016.

[3] OSHA, Reflections on OSHA's History, OSHA, Washington, DC, USA, 2009.

[4] U. Kjellen and E. Albrechtsen, Prevention of Accidents and Unwanted Occurrences: Theory, Methods, and Tools in Safety Management, CRC Press, Boca Raton, FL, USA, 2017.

[5] L. Wang, Y.-P. Cheng, and H.-Y. Liu, "An analysis of fatal gas accidents in Chinese coal mines," Safety Science, vol. 62, pp. 107-113, 2014.

[6] Z. Song and C. Kuenzer, "Coal fires in China over the last decade: a comprehensive review," International Journal of Coal Geology, vol. 133, pp. 72-99, 2014.

[7] W. Cai and S. Q. Ma, "Present status and countermeasures of coal mine safety management in China," Coal Science and Technology, vol. 32, no. 12, pp. 74-76, 2004.

[8] X. J. Lv, H. Zhang, and H. Y. Liu, "Coal mine disaster role of security policy control method based on analysis of ISM," China Safety Science Journal, vol. 22, no. 5, pp. 158-163, 2012.

[9] A. Boughaba, C. Hassane, and O. Roukia, "Safety culture assessment in petrochemical industry: a comparative study of two Algerian plants," Safety and Health at Work, vol. 5, no. 2, pp. 60-65, 2014.

[10] S. J. Yoon, H. K. Lin, G. Chen, S. Yi, J. Choi, and Z. Rui, "Effect of occupational health and safety management system on work-related accident rate and differences of occupational health and safety management system awareness between managers in South Korea's construction industry," Safety and Health at Work, vol. 4, no. 4, pp. 201-209, 2013.

[11] I. Mohammadfam, M. Kamalinia, M. Momeni, R. Golmohammadi, Y. Hamidi, and A. Soltanian, "Evaluation of the quality of occupational health and safety management systems based on key performance indicators in certified organizations," Safety and Health at Work, vol. 8, no. 2, pp. 156-161, 2017.

[12] F. Guldenmund, A. Hale, L. Goossens, J. Betten, and N. Duijm, "The development of an audit technique to assess the quality of safety barrier management," Journal of Hazardous Materials, vol. 130, no. 3, pp. 234-241, 2006.

[13] T. G. Rose, The Management Audit, Gee \& Company, London, UK, 1932.

[14] IIA, International Standards for the Professional Practice of Internal Auditing (Standards), The IIA, Altamonte Springs, FL, USA, 2010.

[15] L. B. Sawyer, Practice of Modern Internal Auditing, The IIA, Altamonte Springs, FL, USA, 1973.

[16] P. Kotler, W. Gregor, and W. Rodgers, "The marketing audit comes of age," Sloan Management Review, vol. 18, no. 2, pp. 25-43, 1977.

[17] G. Y. Wang, "Ten ideas of modern internal audit," The Audit Research, vol. 2, pp. 24-30, 2007.

[18] M. Heath, "Road safety audit UK-A practice summary," Traffic Engineering \& Control, vol. 45, no. 6, 2004.

[19] China CAAo, "Airline safety audit manual," 2007, http:// www.caac.gov.cn/ZTZL/RDZT/MHAQSJ/GJMH/.

[20] D. J. Silk, "Reliability, safety and risk management: an integrated approach," Engineering Management Journal, vol. 2, no. 5, p. 204, 1992.

[21] B. Kirwan, Safety Management Assessment and Task Analysis-A Missing Link, Safety Management: The Challenge of Change Elsevier, vol. 67, p. 92, Oxford, UK, 1998.

[22] HSE, Successful Health and Safety Management (HSG65), Health and Safety Executive, Bootle, UK, 1997. 
[23] S. C. Tian and X. Jing G, Safety Management, China Machine Press, Beijing, China, 2009.

[24] U. Kjellén, K. Boe, and H. L. Hagen, "Economic effects of implementing internal control of health, safety and environment: a retrospective case study of an aluminium plant," Safety Science, vol. 27, no. 2-3, pp. 99-114, 1997.

[25] AICPA, Statement on Auditing Standards No. 47: Audit Risk and Materiality in Conducting an Audit, AICPA, New York, NY, USA, 1983.

[26] P. R. Beaulieu, "The effects of judgments of new clients' integrity upon risk judgments, audit evidence, and fees," Auditing: A Journal of Practice \& Theory, vol. 20, no. 2, pp. 85-99, 2001.

[27] K.-Y. Low, "The effects of industry specialization on audit risk assessments and audit-planning decisions," The Accounting Review, vol. 79, no. 1, pp. 201-219, 2004.

[28] A. A. Arens, R. J. Elder, and B. Mark, Auditing and Assurance Services: An Integrated Approach, Prentice-Hall, Boston, MA, USA, 2012.

[29] J. C. Bédard, "An archival investigation of audit programplanning," Auditing: A Journal of Practice \& Theory, vol. 9, no. 1, pp. 57-71, 1989.

[30] Z. G. Yang and Z. A. Chang, "Research on the causes of audit risk of listed companies," Auditing Research, vol. 4, pp. 27-32, 2004.

[31] P. Liu and F. Jin, "Methods for aggregating intuitionistic uncertain linguistic variables and their application to group decision making," Information Sciences, vol. 205, pp. 58-71, 2012.

[32] L. A. Zadeh, "Fuzzy sets," Information and Control, vol. 8, no. 3, pp. 338-353, 1965.

[33] S. M. Baas and H. Kwakernaak, "Rating and ranking of multiple-aspect alternatives using fuzzy sets," Automatica, vol. 13, no. 1, pp. 47-58, 1977.

[34] S.-J. Chen and C.-L. Hwang, "Fuzzy multiple attribute decision making methods," in Fuzzy Multiple Attribute Decision MakingSpringer, Berlin, Germany, 1992.

[35] X. F. Qi, Research on Multi-Attribute Decision Making Method Based on Interval Intuitionistic Uncertain Linguistic Information, Shandong University of Finance and Economics, Shandong, China, 2015.

[36] K. Yang, Y. Wang, X. Tian, C. Yu, and J. Zhou, "The courting display mechanism of great bustard (otis tarda) in semi grazing," Chinese Journal of Wildlife, vol. 39, no. 2, pp. 340346, 2018.

[37] K. T. Atanassov, "More on intuitionistic fuzzy sets," Fuzzy Sets and Systems, vol. 33, no. 1, pp. 37-45, 1989.

[38] K. Atanassov and G. Gargov, "Interval valued intuitionistic fuzzy sets," Fuzzy Sets and Systems, vol. 31, no. 3, pp. 343-349, 1989.

[39] K. T. Atanassov, "Interval valued intuitionistic fuzzy sets," in Intuitionistic Fuzzy Sets, pp. 139-177, Springer, Berlin, Germany, 1999.

[40] J. Q. Wang and J. J. Li, "Multi criteria group decision making method based on multi granularity intuitionistic binary semantics," Scientific and Technological Information, vol. 33, 2009.

[41] X. Wang, J. Wang, and S. Deng, "Some geometric operators for aggregating intuitionistic linguistic information," International Journal of Fuzzy Systems, vol. 17, no. 2, pp. 268-278, 2015.

[42] Y. Ju and S. Yang, "A new method for multiple attribute group decision-making with intuitionistic trapezoid fuzzy linguistic information," Soft Computing, vol. 19, no. 8, pp. 2211-2224, 2014.

[43] Y. Zhang, H. Ma, B. Liu, and J. Liu, "Group decision making with 2-tuple intuitionistic fuzzy linguistic preference relations," Soft Computing, vol. 16, no. 8, pp. 1439-1446, 2012.

[44] P. Liu, "Some geometric aggregation operators based on interval intuitionistic uncertain linguistic variables and their application to group decision making," Applied Mathematical Modelling, vol. 37, no. 4, pp. 2430-2444, 2013.

[45] C. Liu, G. Tang, and P. Liu, "An approach to multicriteria group decision-making with unknown weight information based on Pythagorean fuzzy uncertain linguistic aggregation operators," Mathematical Problems in Engineering, vol. 2017, Article ID 6414020, 18 pages, 2017.

[46] S. Zeng, M. Qiyas, M. Arif, and T. Mahmood, "Extended version of linguistic picture fuzzy TOPSIS method and its applications in enterprise resource planning systems," Mathematical Problems in Engineering, vol. 2019, Article ID 8594938, 8 pages, 2019.

[47] C.-L. Hwang and K. Yoon, "Methods for multiple attribute decision making," in Multiple Attribute Decision MakingSpringer, Berlin, Germany, 1981.

[48] D. Choudhary and R. Shankar, "An STEEP-fuzzy AHPTOPSIS framework for evaluation and selection of thermal power plant location: a case study from India," Energy, vol. 42, no. 1, pp. 510-521, 2012.

[49] Y. T. Ic and M. Yurdakul, "Development of a quick credibility scoring decision support system using fuzzy TOPSIS," Expert Systems with Applications, vol. 37, no. 1, pp. 567-574, 2010.

[50] J. Tabor, "Application the fuzzy TOPSIS method to assess and select a contractor from the point of view of occupational safety management," Quality-Access to Success, vol. 20, 2019.

[51] J. Tabor, "Fuzzy TOPSIS in the assessment of OHS management system," System Safety: Human-Technical Facility-Environment, vol. 1, no. 1, pp. 18-25, 2019.

[52] G. Wang and W. Zhao, "Comprehensive evaluation of risk factors of coal mine safety management based on combined weighted tissue model," IOP Conference Series: Earth and Environmental Science, IOP Publishing, Bristol, UK, 2019.

[53] M. Gul, M. F. Ak, and A. F. Guneri, "Pythagorean fuzzy VIKOR-based approach for safety risk assessment in mine industry," Journal of Safety Research, vol. 69, pp. 135-153, 2019.

[54] M. W. Khan, Y. Ali, F. De Felice, and A. Petrillo, "Occupational health and safety in construction industry in Pakistan using modified-SIRA method," Safety Science, vol. 118, pp. 109-118, 2019. 